\section{The Implementation of the Next Generation Science Standards and the Tumultuous Fight to Implement Climate Change Awareness in Science Curricula}

\author{
Christopher Holland \\ Drexel University
}

\section{Brock Brock Education Journal}

A journal of educational research and practice 2020 Vol. 29 (1) 35 - 52

https://journals.library.brocku.ca/brocked

\begin{abstract}
The following article examines the implementation and controversy that surround climate change education and the implementation of the Next Generation Science Standards (NGSS). In order to fully understand why NGSS and climate change education continue to generate significant public debate, one must examine the work of both climate advocates and detractors. Therefore, this paper first examines the manner in which climate change continues to remain a debatable topic of discussion throughout American classrooms despite overwhelming scientific consensus. After, it explores how the debate over climate change stems from differing ethical cornerstones. Moreover, it delves into the oppositional perspective on climate change implementation by exploring the work of Truth in Textbooks Coalition (TNT). Subsequently, it introduces and analyzes the creation and implementation of NGSS and discusses how adoption of NGSS and stronger levels of opposition to TNT is responsive policy that remains a necessary step to challenging global issues created by climate change.
\end{abstract}

Keywords: Climate Change, NGSS, Curriculum, Standards 
President Donald Trump's announcement in June 2017 that the United States intended to withdraw from the Paris climate agreement continues to receive both praise and critique from private citizens, public policy organizations, the scientific community, and world leaders (BBC News, 2017). The decision to pull away from the international agreement was one of several actions that the Trump administration enacted to reduce environmental protections and dismantle climate change policies created and/or continued under the Obama administration (i.e. repeal of the Clean Power Plan) (Friedman, 2017). Although several state governors vowed to uphold clean power standards and comply with goals of the Paris climate agreement, without more significant attention to the issue of climate change the US government will fail to meet the overall goals of the agreement (Plumer, 2017). Moreover, non-compliance will only create more undesirable outcomes across the world, especially within impoverished communities (Provost, 2016). Therefore, as political controversy continues to spread throughout the United States, reformers continue to look towards schools to educate and empower students to tackle climate change in order to alleviate future catastrophe for those in and barely out of extreme poverty (Harmon, 2017). Within this context, this paper explores perspectives that surround climate change education and the implementation of the Next Generation Science Standards (NGSS) while calling on schools within the United States to implement curricula that is responsive to the growing threat of climate change.

\section{Climate Change in Context}

Climate change continues to threaten the well-being of people across the world, especially among populations living in impoverished conditions. The following section provides background information about how American schools continue to debate the existence of climate change despite the prevalence of threatening natural conditions.

\section{Climate Change Science}

As the earth progresses further into the 21 st century, climate change continues to pose serious risks to humans across the world (United Nations, 2015). According to the National Aeronautics and Space Administration (NASA), ninety-seven percent of climate scientists agree that worldwide warming trends over the past 100 years are the result of human activity since the Industrial Revolution (NASA, 2017). Specifically, industrialization led to rapid increases in carbon dioxide emission that the earth had never experienced before (NASA, 2017). The result of this continues to be catastrophic for global communities as world temperatures rose about 2.0 degrees Fahrenheit since 1900, leading to oceans warming considerably, ice sheets continually shrinking, and glaciers retreating (NASA, 2017; Zhou, Chen, Li, Wang, \& Zhang, 2017). This temperature change results in rising sea levels that can potentially threaten coastal populations across the world, as they are at or below sea level (NASA, 2017). Extreme weather events such as hurricanes and droughts will become stronger over time and threaten the lives of people across the world (NASA, 2017). Finally, through a process of acidification, maritime ecosystems continually change and threaten species with extinction (NASA, 2017). Social scientists overwhelmingly agree that the populations that will experience the most detrimental effects of climate change are those from impoverished communities. As a result, it is important to understand climate change as intrinsically tied to worldwide poverty. 


\section{Global Poverty}

The United Nations' (2015) Sustainable Development Goals refers to poverty as a $21_{\text {st }}$ century problem in need of resolution. Specifically, the eradication of poverty is not only specifically mentioned as the organization's first goal, but it is also a focal point across the other 16 goals (United Nations, 2015). Compounding issues like hunger, access to strong educational opportunities, and a reduction in socioeconomic, racial, and gender equality all refer to the need to reduce worldwide poverty levels (United Nations, 2015). Interestingly, worldwide poverty rates continue to decline since 1990 (Leary, 2016; Jackson, 2017). According to the World Bank, in 2013, 767 million people relied on \$1.90 USD a day (Leary, 2016), and this is significantly lower than 1990 where 1.85 billion people relied on that same amount (Leary, 2016). The strongest levels of improvement were most evident in Asian nations like China, Indonesia and India (Leary, 2016).

Despite these improvements, overall poverty reduction remains uneven. Just as nations like China, Indonesia, and India have seen improvement, poverty rates remain stagnant in SubSaharan Africa (Leary, 2016). Although it appears that the global community's efforts to end poverty has made great strides, additional studies found that when one raises the \$1.90 USD standard to \$3.10 USD, arguably a more realistic and adjusted standard for extreme poverty markers, the aforementioned "progress" presents a bleaker outlook (Jackson, 2017).

\section{Climate Change and Global Poverty}

According to the World Bank, climate change remains a strong threat to impoverished communities across the world and has the power to push as many as 100 million people into poverty over the next 15 years (Hallegatte et al., 2016). According to Jackson (2017), much of the climate risks that impoverished communities experience are the result of three factors: exposure to extreme weather events, poor infrastructure and resources, and lower abilities to adapt to climate change conditions. Taken together, these factors present various challenges for poorer populations that bear witness to climate change concerns like food scarcity, diminished health conditions, and violence (Hallegate, et al., 2016; Jackson, 2017; Otto et al., 2017; Provost, 2016; Zhou et al., 2017).

Climate change significantly impacts hungry populations. Based off of research conducted by Ertharin Cousin of the World Food Programme, Provost (2017) explains that over $80 \%$ of the world's hungriest populations lives in areas prone to both natural disasters and environmental degradation. Additionally, for remote rural communities climate change has significantly harmed food supplies in two major ways (Provost, 2017; Zhou et al., 2017). First, stronger climate events such as droughts and storms have instantly destroyed agricultural resources. Second, diminished food supplies lead to inflated prices that exceed amounts considered reasonable for those living in, or barely out of, poverty (Provost, 2017; Zhou et al., 2017).

Climate change also has the potential to create public health crises for impoverished populations (Jackson, 2017). Evidence suggests that a correlation exists between socioeconomic status and health inequality (Otto et al., 2017), as individuals who live in poverty tend to show signs of poorer health than those that have wealth. For example, food scarcity that is the result of 
climate change amplifies the threat of malnutrition and its negative impact on the physical, mental, and psychological development of children (Otto et al., 2017). Furthermore, waterborne diseases and environmental degradation continues to harm people within poor communities, as they lack necessary resources to migrate away from natural disaster zones (Otto et al., 2017). Finally, research suggests that impoverished populations disproportionately contend with polluted air, unsafe water sources, and sewage treatment problems on a regular basis (Jackson, 2017; Otto et al., 2017).

In addition to creating unequal environmental and health conditions, climate change within disadvantaged communities may lead to significant increases in violence. Otto et al. (2017) discuss how depletion of resources led farmers and herders of the Sahel region to fight over minimal water reserves (p. \#). Additionally, climate change has forced some women, who are often tasked with transporting water and fuel in many cultures, to walk further distances to find resources, and as discussed by Otto et al. (2017), this opens them up to longer periods of exposure to both harassment and sexual assault (p. \#).

As outline above, increased violence, combined with food scarcity and public health concerns, disproportionately affect poor communities across the world and strongly hinder future progress on several of the United Nations Sustainable Goals (United Nations, 2015). Unfortunately, given the current political landscape of the United States, debate over the merits of scientific research continue to distract education policymakers from developing curricula that enables students to understand climate change as a significant issue for all individuals and especially those who comprise vulnerable populations.

\section{The Climate Change Debate in Schools}

The debate over the validity of climate change as acceptable scientific knowledge continues to rage on within spaces of public discourse. In particular, schools continue to present significant opportunities for policymakers and other stakeholders to push scientific, social, and religious agendas that can either support or counter climate change (Foran, 2014; Harmon, 2017). Despite overwhelming evidence and a strong consensus among climate scientists that human-generated climate change exists, many individuals and groups continue to perceive climate change as an attack on traditional values and religious dogma (Foran, 2014). The result of this debate has been catastrophic for those who believe climate change should be a central part of school curricula.

According to one study, most science teachers spend less than two hours of scholastic time during the year to address climate change (Harmon, 2017; Goldenberg, 2016). Even worse, because most educators have not received proper training in teaching the topic, many have misconceived notions about climate change (Kirk, 2017). According to Kirk (2017), 70 percent of middle school and 55 percent of high school teachers did not know that a consensus existed that climate change was the result of human activity. Moreover, according to Goldenberg (2016), nearly two-thirds of students receive an inadequate education when it comes to climate change. Specifically, according to a report from Science, only 38 percent of educators taught a curriculum that adhered to universally accepted suggestions that climate change is the result of fossil fuel consumption (Goldenberg, 2016). Additionally, 22 percent of educators falsely taught 
lessons that presented climate change as a topic with significant disagreement among scientists (Goldenberg, 2016).

This inadequate coverage and preparation of climate change curricula creates a wedge that allows climate denial groups to continually influence educational policy. The result of this is a fierce debate that stems from differing worldviews and ethical perspectives. The following section describes how the climate change curricula debate boils down to differing ethical lenses.

\section{Opposing Responses to Climate Change Education}

Examination of the climate change debate in schools requires an understanding of how utilitarian framework and Rawls' theory of justice as fairness contradict. First, a utilitarian ethical framework allows for researchers and practitioners to choose policy that generates the greatest benefit to the most people (Deigh, 2010). With regards to the climate change debate, those in favor of including climate change by adopting the Next Generation Science Standards (NGSS) emphasize focusing on identifying issues, forming solutions, and preventing irreversible climate damage that can harm future generations. As a result, NGSS planners envisioned their work as promoting the welfare of vast majorities of American and global populations by minimizing threatening situations around the world and forming sustainable solutions to climate change issues.

On the other hand, NGSS detractors like the group Truth in Textbooks Coalition (TNT) rely on core ideals of Rawls' theory of justice as fairness to call on schools to remain impartial and offer all sides of the climate change debate in a manner that is deemed equal (Cornwall Alliance (CA), 2017; TAE, 2017; TNT, 2017). This group's disregard for scientists' overwhelming consensus, along with their attempt to place a "veil of ignorance" over the debate remains an attempt to divorce climate change from any social, economic, or political consideration (CA, 2017; Truth in American Education (TAE), 2017; TNT, 2017). As a result, these anti-climate change groups often label their mission as a quest for fairness and justice, similar to the philosophical beliefs of Rawls $(2001 ; 1999)$.

Within the context of the aforementioned ethical frameworks, educational reformers continue to impose ideologically opposing views about climate change into curricula. The following section analyzes these perspectives by examining the work of TNT and proponents of NGSS.

\section{Truth in Textbooks Coalition (TNT)1}

Since it was founded in 2013 by retired Lieutenant Colonel Roy White, TNT aims to improve the accuracy of textbooks and curriculum resources for students enrolled in PreK-12 Texas schools (TNT, 2017). In addition to being an Air Force veteran who completed tours in Desert Storm and Operation Enduring Freedom, White has experience as a social studies teacher and commercial pilot for Southwest Airlines (Michels, 2014; TNT, 2017). His organization, TNT, is comprised of citizen volunteers concerned about the way in which controversial issues

1 The Truth in Texas Textbooks (TTT) changed its name to Truth in Textbooks Coalition (TNT) as it received popular response beyond Texas to include movements in other states in the United States. 
like climate change, patriotism, religion, and evolution are presented to students (Michels, 2014; TNT, 2017). One service TNT provides to school districts is content analysis of required textbooks. To become a book reviewer, volunteers complete a three-month training regimen and are split into teams of four that meet remotely over conference calls to debate and discuss their evaluations of different textbooks (TNT, 2017). In 2014 alone, the former TNT reviewed 32 middle and high school textbooks ahead of the State Board of Education's decision to adopt certain books across the state (TNT, 2017).

Although TNT members label themselves as non-partisan and non-religious, journalists label their agenda as both pro-Christian and conservative in its investigation of American history, politics and values (Foran, 2014; Michels, 2014). Moreover, TNT leaders' abilities to recruit among Tea-Party networks and church groups make the organization staunchly conservative in their approach to schools and curricula (Foran, 2014). In an early review of textbooks, TNT reviewers admonished publishers that did not label jihad as a violent struggle (TNT, 2015). They also called for publishers to discuss the influence of the Ten Commandments and other Judeo-Christian dogma on American society (TNT, 2015). Finally, they advocate for a "balanced approach" to both evolution and climate change, demanding that textbooks mention rationales for both creationism and climate denial (Foran, 2014; Michels, 2014; TNT, 2015).

TNT functions beyond textbook evaluations. Specifically, their public advocacy and recruitment efforts continue to expand throughout more Conservative communities. Through their public advocacy efforts, TNT releases their textbook review reports to citizens free of charge, attends and actively participates in State Board of Education meetings, and discusses their mission and core values to the press (Foran, 2014, Michels, 2014; Stutz, 2014; TNT, 2017). Aside from the 469-page report that identified textbook mistakes, TNT played a significant role in politicizing the 2014 State Board of Education textbook adoption hearings (Stutz, 2014). According to Michels (2014), TNT's role in publicly denouncing textbook errors made the group a premier organization for conservatives who display reservations over the content projected in curriculum resources. As a result of their public advocacy efforts, TNT encouraged conservative citizens to write to school board officials and pressure textbook publishers to make corrections to their materials (Michels, 2014).

As mentioned, TNT prides itself on its recruitment efforts. According to TNT, by the end of 2017 the organization will have around 200 volunteers who have completed the three-month training process (TNT, 2017). Overall, the organization hopes to include 500 volunteers, all of whom will be trained in textbook review and ready to assist teachers, parents, and others in locating available materials that make curricula "more accurate" (TNT, 2017, p. \#). Furthermore, their recruitment efforts extend beyond Texas, as TNT has publicly expressed excitement over the prospect of working with similar movements in other states (Foran, 2014). Specifically, TNT's influence continues to play a strong role in how reformist groups rate textbooks in California, Florida, Indiana, Maine, Nevada, Ohio, Utah, and Wisconsin (Foran, 2014). The group assists the 22 states that have a centralized textbook review process in evaluating course materials (TNT, 2017). In that respect, TNT's public advocacy of conservative values and climate denial continues to play a strong role in how textbooks are adopted beyond Texas' state borders. 
Given TNT's conservative stance, one can surmise that it assumes a strong climate denial perspective and seeks to use anti-climate change rhetoric to argue for curricular reform. TNT's 469-page report includes several specific references to textbooks' approaches to discuss climate science (TNT, 2015). Review of these reprimands results in the emergence of three different arguments that TNT relies on to base their claims against the existence of human-made climate change. First, they view climate change as a theory that has yet to be proven (TNT, 2015). Despite overwhelming consensus from the scientific community about the presence of humanmade climate change, TNT points to a 2007 climate study from the Oregon Institute of Science and Medicine that concludes that there is no convincing scientific evidence that carbon dioxide, methane, or other greenhouse gases contribute to climate disruption (TNT, 2015). They also point towards a petition signed by 31,487 scientists that suggest climate change is the result of natural and not human activity (TNT, 2015).

Moreover, the TNT utilize NASA data to refute the claim that climate change influenced weather events have created disturbances in agricultural production. Specifically, they point to a NASA study that suggests $95 \%$ of solar radiation never reaches the earth because it is reflected from both carbon dioxide and nitrogen oxide (TNT, 2015). They claim that these gasses form a protective atmospheric shield that reflects otherwise dangerous levels of solar radiation that would melt polar ice caps and destroy ecosystems across the earth (TNT, 2015). Therefore, in addition to arguing that climate change is still a theory without consensus or strong evidence, TNT points carbon dioxide and nitrogen oxide as being necessary atmospheric gasses that prevent annihilation.

Finally, TNT argues that climate change is natural and nothing that warrants an alarmist mentality. Specifically, they point to scientific evidence of the earth cooling and warming over the course of its existence to suggest that current climate change arguments do not reflect reality and only serve to frighten people (TNT, 2015). TNT claim that slight changes in the patterns of the earth's orbit, varying energy from the Sun, and increased greenhouse gasses are all results of fossil fuel consumption that increase temperatures in a way that is both safe and destined to decline in the future (TNT, 2015). Taken together, these three arguments form the major claims that TNT uses to encourage publishers to revise textbooks and present a more balanced argument that includes perspectives that are both in favor of and against climate change. One current foci of TNT's efforts to discredit climate change curricula continues to be the Next Generation Science Standards (NGSS).

\section{Next Generation Science Standards (NGSS)}

In relation to the issue of climate change education, NGSS seeks to better incorporate the issue in science classrooms across the nation (NGSS Lead States, 2013). Specific analysis of NGSS' standards reveal that climate change remains integrated throughout its guidelines for classrooms across middle and secondary school curricula (Alliance for Climate Education 2017). In Appendix A, there is an excerpt of standards that pertain to climate change education, compiled and released by the Alliance for Climate Education (ACE) (ACE, 2017). Analysis of these standards suggest that NGSS approaches climate change as a researchable and significant topic for consistent student inquiry, and frames climate change as the result of human activity (ACE, 2017; NGSS Lead States, 2013). In regard to other state science standards, NGSS stands 
as the strongest in its integration of human-influenced climate change in K-12 science curricula (ACE, 2017; Bidwell, 2014). In this respect, I will investigate how NGSS was formed and implemented by 19 states and the District of Columbia.

The Next Generation Science Standards is the result of collaborative inquiry and a structured, deliberate process supported by the National Research Council of the National Academy of the Sciences (NRC), National Science Teachers Association (NSTA), American Association for the Advancement of Science (AAAS), and Achieve (Robelen, 2012).

Specifically, these groups completed a two-stage process to create these standards. First, the NRC drafted a preliminary framework by identifying science content that every K-12 student should know and grounding potential avenues of academic inquiry in the most up-to-date research (Branch, 2013; NGSS Lead States, 2013).

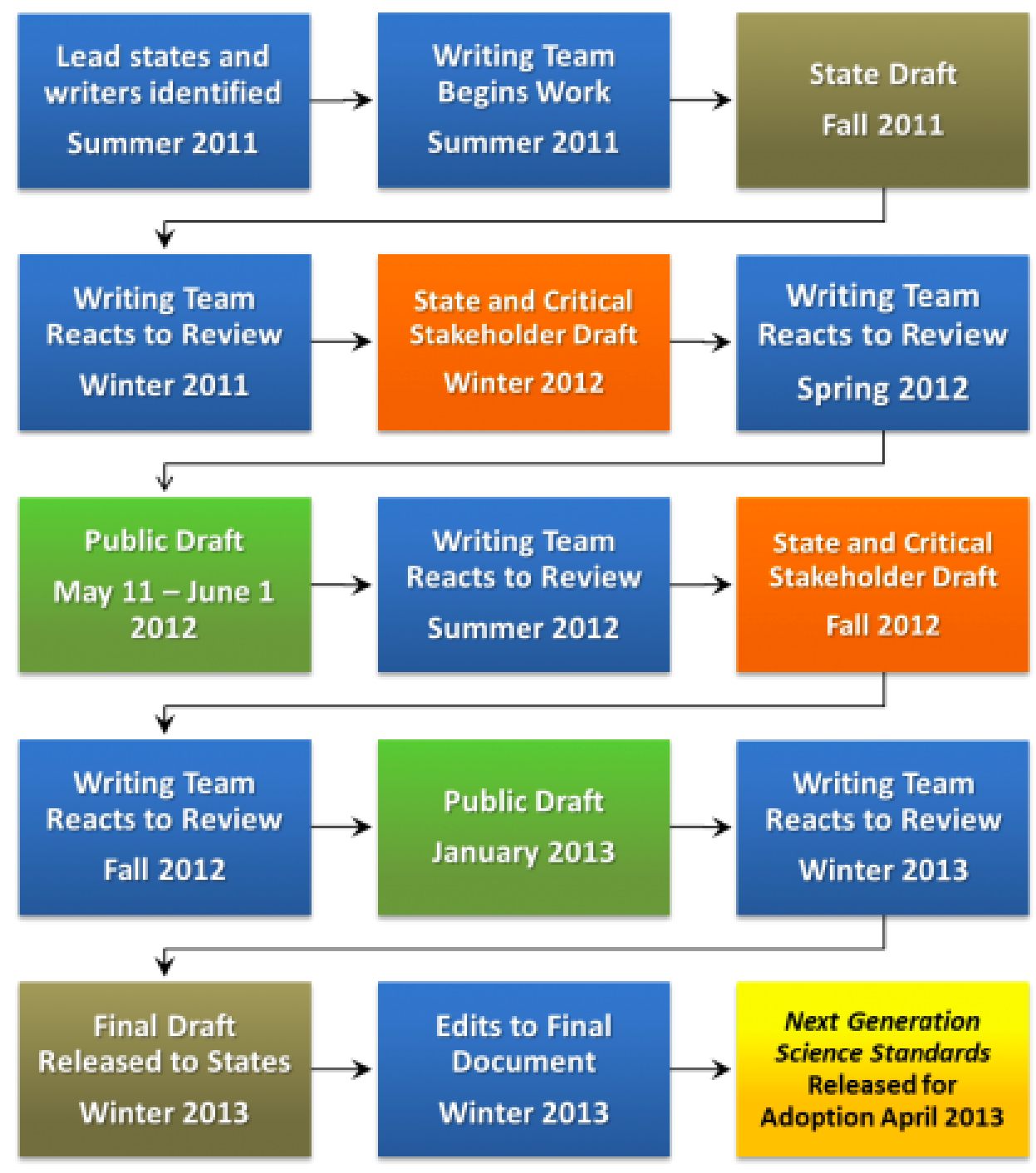

Figure 1: Visual representation of the second stage of the NGSS completion process (NGSS Lead States, 2013). 
Members of the NRC group that completed this framework included policymakers, leading scientists, Nobel Prize laureates, cognitive experts, and science education researchers (NGSS Lead States, 2013). Frameworks were created in physical science, life science, earth/space science, and engineering (NGSS Lead States, 2013). The NRC's findings were released to the public in July 2010 and NRC received comments/feedback until the final framework was released on July 19, 2011 (NGSS Lead States, 2013).

Once this stage was complete, the responsibility to create standards fell on the shoulders of state participants. Managed by Achieve, an independent, nonpartisan nonprofit organization dedicated to improving scholastic outcomes for preK-12 students, states were tasked with creating standards that were rich in content and arranged in a coherent pattern according to international benchmarks and efforts to prepare students for college and future careers (NGSS Lead States, 2013). Through multiple periods of revision, stakeholders from schools, governmental organizations, private industries, and higher education had an opportunity to influence the development of these standards (NGSS Lead States, 2013). The final draft was released in April 2013 after providing several opportunities for the public to review and question the standards' content. Figure 1 is a visual depiction of the stage 2 process that lasted from 2011 to 2013.

\section{Implementation}

Once created, the decision to adopt NGSS as official fell on the shoulders of state education departments and local school districts. To assist schools in making the transition to adoption of the standards, NGSS policymakers created an implementation guidebook to aid classroom educators, school administrators, districts officials, and state lawmakers in their transformation (NRC, 2015). Specifically, the NRC called upon schools to create coherence across schools, grade levels, curricula, assessment, instructional design, and professional development programming (NRC, 2015). According to the NRC, successful adoption hinges on targeting learning communities and providing opportunities to examine the uniqueness of science, collaborate with networks of science professionals, and allocate enough time to properly implement each standard (NRC, 2015). Finally, by offering support for state, district, and school leaders responsible for implementation, the NRC suggests that participating programs make educational equity a priority and maintain ongoing and relevant communication about the successes and failures of execution (NRC, 2015).

Incorporation of NGSS in science curricula requires schools, districts, and states to adjust their approach to science education by integrating more hands-on, research experiences for students (NRC, 2015). Moreover, evidence-based classroom learning should be encouraged by participating schools (NRC, 2015). With regards to teacher and administrator learning, implementation mandates the creation and maintenance of strong professional development opportunities (NRC, 2015). In terms of curriculum materials, the NRC recognizes that successful implementation requires that NGSS officials release relevant classroom materials for educators tasked with enacting new styles of teaching and learning (NRC, 2015). Assessments should shift away from "knowledge of facts" and move towards a more holistic, hands-on assessment of learning that aligns to NGSS performance standards (NRC, 2015). Finally, 
implementation requires NGSS officials to create spaces for collaboration among networks of school professionals dedicated to sharing best practices and course resources (NRC, 2015).

Therefore, with regards to NGSS, implementation requires a shift in how science education was previously conceptualized and presented to students. By transitioning from a more traditional, knowledge-based form of learning, NGSS requires schools to adopt a more evidence-based, hands-on learning pedagogy. Although some states continue to show support for NGSS, it has not been considered a welcomed reform in more conservative education departments.

\section{Statewide Enactment}

In relation to federal policy, NGSS supports principles and learning standards listed in Common Core for K-12 settings (NGSS Lead States, 2013). At the same time, national educational policy on standards, especially in science, remain limited and in need of further explanation (Common Core State Standards Initiative, 2017; Williams, 2013). In that respect, states control the power to enact NGSS. This pattern of decentralization in the United States education system stems from the 9th Amendment, which protects states' powers to dictate education policy within their jurisdiction. As a result, the manner in which schools, districts, and governments enact NGSS remains a more decentralized act that requires individual states to accept the standards (NGSS Lead States, 2013).

When standards were written prior to its roll out in 2013, 26 states participated in the creation process (NGSS Lead States, 2013). Since then, these states, along with 14 additional ones, expressed interest in developing a set of standards that would create continuity among districts in these states, consider international science progress markers, and participate in the collaborative development of assessments and curricula (NGSS Lead States, 2013). Table 1 chronologically explains the growth of NGSS since its inception in 2010.

\section{Table 1}

Development and Implementation Milestones of NGSS

\section{Date}

Milestone

July 2010

July 2011

Fall 2011

May 2012

Jan. 2013

April 2013

May 2013

June 2013

June 2013

June 2013

\section{Developmental Milestones}

NRC releases draft of NGSS framework for public review and feedback. NRC finalizes NGSS framework. State Partners draft NGSS and release it to writing teams for review. Revised draft of NGSS released to public for review and feedback. Newly revised draft of NGSS released to public review and feedback. NGSS released to schools, districts, and states for adoption.

\section{Implementation Milestones}

Rhode Island becomes the 1 st state to adopt NGSS

Kansas becomes the 2nd state to adopt NGSS.

Maryland becomes the 3rd state to adopt NGSS.

Vermont becomes the 4th state to adopt NGSS 
Sept. 2013

Sept. 2013

Sept. 2013

Oct. 2013

Dec. 2013

March 2014

March 2014

March 2014

July 2014

June 2015

Nov. 2015

Nov. 2015

Jan. 2016

Feb. 2016

Nov. 2016

Nov. 2017
California becomes the 5 th state to adopt NGSS.

Kentucky becomes the 6th state to adopt NGSS (after political disputes)

Delaware becomes the 7 th state to adopt NGSS

Washington becomes the 8th state to adopt NGSS

District of Columbia adopts NGSS.

Nevada becomes the 9 th state to adopt NGSS.

Oregon becomes the 10th state to adopt NGSS.

Illinois becomes the 11 th state to adopt NGSS.

New Jersey becomes the 12th state to adopt NGSS.

Arkansas becomes the 13th state to adopt NGSS.

Connecticut becomes the 14th state to adopt NGSS

Michigan becomes the 15 th state to adopt NGSS.

Iowa becomes the 16th state to adopt NGSS.

Hawaii becomes the 17 th state to adopt NGSS.

New Hampshire becomes the 18th state to adopt NGSS.

New Mexico becomes the 19th state to adopt NGSS.

Note: Developmental milestones were compiled using NGSS (NGSS Lead States, 2013). Implementation milestones were adapted from the state/city education department websites for each of the state that voted to implement NGSS.

As of November 2017, 19 states, along with the District of Columbia, chose to adopt NGSS as their state science standards (Branch, 2017; National Science Teachers Association, 2017). These states include: Arkansas, California, Connecticut, Delaware, Hawaii, Illinois, Iowa, Kansas, Kentucky, Maryland, Michigan, Nevada, New Hampshire, New Mexico, New Jersey, Oregon, Rhode Island, Vermont, and Washington (NSTA, 2017). Figure 2 is a visual representation of the states that adopted NGSS as of November 2017.

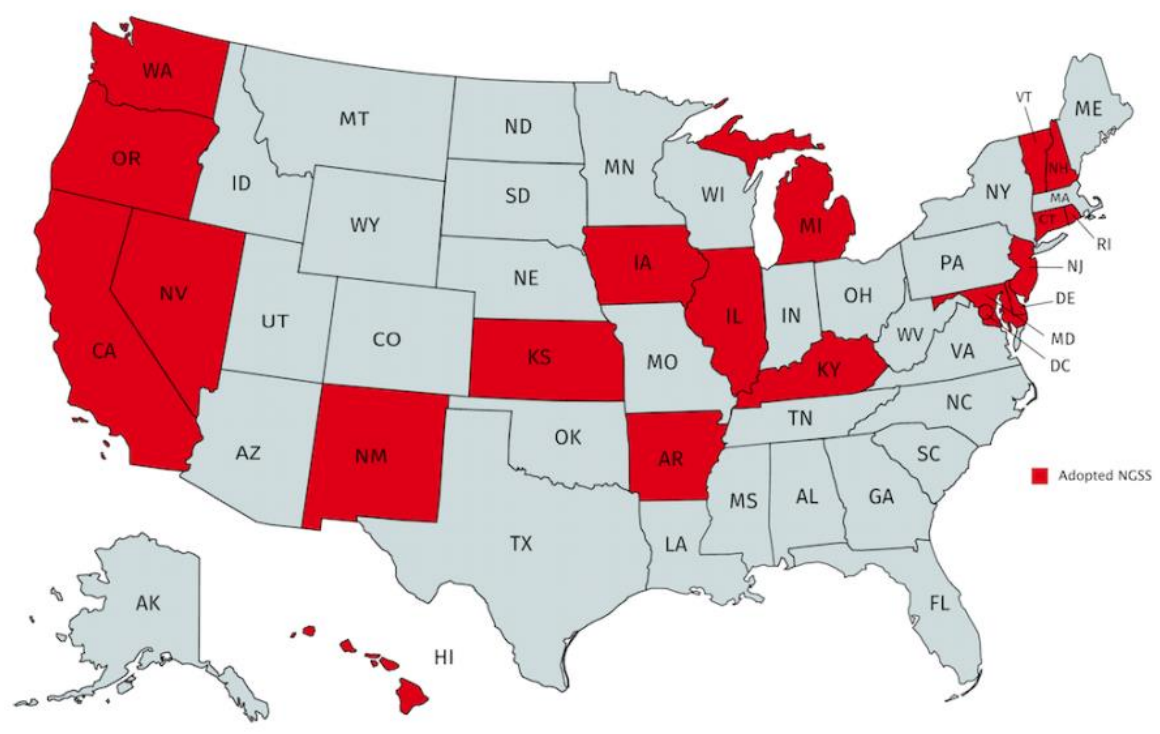

Figure 2: Map of states that adopted NGSS as of November 2017 (NSTA, 2017). 
According to Gillis (2013), although expected to be quickly adopted by most states, NGSS' training, professional development, and curricular shifts continue to slow the process of curricular implementation within many states. Additionally, because adoption of NGSS is voluntary and without federal support or consequence, overall desire to adopt new, transformative standards have not received the support that NGSS leaders expected. Finally, several groups, like Truth in Textbooks (TNT) continue to hamper efforts to adopt these standards. TNT, Truth in American Education (TAE), and the Cornwall Alliance (CA) see NGSS as an attack on traditional American and religious values (CA, 2017). These groups label NGSS as a form of liberal indoctrination (TAE, 2017; TNT, 2017). Moving forward, school leaders must consider the consequences of adopting or rejecting NGSS and choose policies responsive to realistic global trends and conditions.

\section{Responsive Educational Policy}

Given the uncertain political climate that swirls around climate change in the United States, policymakers up to this point have failed to form a consensus on an appropriate way to address climate change and its influence on global poverty in school curricula (Bidwell, 2014; Franko, 2017; Harmon, 2017). Unfortunately, disagreement among educational policymakers will continue as long as the nation remains divided in its understanding of human made climate change. Within this context, the future of NGSS is subject to political influence from both proponents and dissenters of climate change education.

The current political attitude of the Trump administration to reduce the scope of national influence over education creates a doubtful situation for national adoption of NGSS (Finn, 2017; Hansen, Mann \& Valant, 2017). Evident in massive budgetary cuts to national education programs, Trump's campaign to abolish Common Core (and for that matter, the entire US Department of Education) provides states with significant power over educational policy (Hansen, Mann \& Valant, 2017; US Department of Education, 2017). With regards to NGSS, if the administration continues to dismantle national curricula models and educational programs, survival will depend on statewide adoption. While many blue and red states adopted NGSS in its first four years of existence, a majority of states have yet to seriously consider enactment, labeling the standards as either biased in its approach to climate change and evolution, or slow in its implementation plan (Chang, 2016; Gillis, 2013). Therefore, operating from the assumption that responsive educational policies investigate situations and generate strong reactions that address and resolve issues, I recommend three policy actions that address climate change integration, in addition to NGSS adoption and compliance.

My first recommendation is that prior to creating any plan to further integrate climate science into school curricula, responsible policymakers must accept that the climate is changing as a result of human activity. Failure to accept the overwhelming evidence and significant consensus among climate scientists is not only a rejection of academic knowledge but also reckless endangerment of current and future global communities. Once accepted, responsible policymakers can move forward to construct policies and programs that fulfill NGSS, educate students about the local and global threat that climate change poses, and create meaningful opportunities for students to discuss possible solutions to climate and poverty issues. 
Second, in order to ensure that students who deny climate change reexamine their beliefs and accept evidence that climate change is the result of human activity, greater opportunities should exist to move climate change to a more focal component of classroom content. This begins by raising educators' awareness of the issue. Based on Kirk's (2017) findings, policymakers should create, fund, and require that established teachers attend professional development programs for those who do not have prior training in climate science or its social impact. Collegiate education programs should foster opportunities for pre-service educators across a wide array of disciplines to learn and apply climate change in their teaching practices. Doing so would encourage future teachers to address the issue in a variety of ways and will leave students with an interdisciplinary core of knowledge that they can apply to their own lives.

Moreover, policymakers should require educators to devote more time to studying climate change in their classrooms than the aforementioned two hours that most classes currently enact (Harmon, 2017; Goldenberg, 2016). Stronger roadmaps should be constructed that clearly outline how educators should address climate change in their courses (Harmon, 2017), and I emphasize that discovery, inquiry-based, and hands-on learning should be paramount. Students must have strong experiences learning about climate change to develop deeper understandings of its role throughout the world. A more global experience will also introduce students to the many different ways climate change influences impoverished communities outside of the United States. In addition to thee points, I believe policymakers should construct a set of prepared responses for teachers to use whenever they are confronted with students who espouse climate denial propaganda.

Finally, responsible policymakers must create learning opportunities that expand climate change curricula beyond science classrooms. Learning in the twenty-first century requires a breakdown of disciplinary barriers that traditional curricula have supported. Since climate change is a contemporary issue in need of new and innovative solutions, students should examine this problem across all disciplines. This should not be highly difficult considering that climate change is highly applicable to interdisciplinary approaches to teaching and learning. Students should understand the social dimension of climate change and have opportunities to engage with others from around the world to construct responsive solutions that curb our carbon dioxide emissions and empower those in poverty to improve their socioeconomic conditions. Understanding the science of climate change is extremely important; however, it must be analyzed through the context of social, political, and economic conditions from around the world if future progress is to be both meaningful and sustainable.

\section{References}

Alliance for Climate Education. (2017). Next Generation Science Standards (NGSS). Retrieved from https://acespace.org/standards/ngss

BBC News. (2017, June 1). Paris climate deal: Trump pulls out of 2015 accord. BBC News. Retrieved from http://www.bbc.com/news/world-us-canada-40127326

Bidwell, A. (2014, June 20). Climate change debate: Coming soon to a school near you. US News and World Report. Retrieved from 
https://www.usnews.com/news/articles/2014/06/20/how-the-climate-change-debate-isinfluencing-whats-taught-in-schools

Branch, G. (2013, April 9). Evolution and climate change in the NGSS. National Center for Science Education, Inc. Retrieved from https://ncse.com/news/2013/04/evolutionclimate-change-ngss-0014800

Branch, G. (2017, November 14). Victory in New Mexico. National Center for Science Education, Inc. Retrieved from https://ncse.com/news/2017/11/victory-new-mexico0018648

Chang, L. (2016, April 24). Court to Kansas group: 'No, school science curriculum is not unconstitutional'. Digital Trends. Retrieved from https://www.digitaltrends.com/web/kansas-ngss/

Common Core State Standards Initiative. (2017). English Language Arts standards: Science and technical subjects. Common Core State Standards Initiative. Retrieved from http://www.corestandards.org/ELA-Literacy/RST/introduction/

Cornwall Alliance. (2017). About. Cornwall Alliance. Retrieved from http://cornwallalliance.org/about/

Deigh, J. (2010). An introduction to ethics. New York, NY: Cambridge University Press. Finn, C. E. (2017, May 3). Education changes in Trump's first 100 days. Thomas B. Fordham Institute. Retrieved from https://edexcellence.net/articles/education-changes-in-trumpsfirst-100-days

Foran, C. (2014, December 8). The plan to get climate change denial into schools. The Atlantic. Retrieved from https://www.theatlantic.com/education/archive/2014/12/the-plan-to-getclimate-change-denial-into-schools/383540/

Franko, K. (2017, June 20). Should climate change be taught in schools?. US News and World Report. Retrieved from https://www.usnews.com/news/best-states/ohio/articles/2017-0620/debate-heats-up-over-teaching-climate-change-in-us-schools

Friedman, L. (2017, October 4). Trump takes a first step toward scrapping Obama's global warming policy. New York Times. Retrieved from https://www.nytimes.com/2017/10/04/climate/trump-climate-change.html

Gillis, J. (2013, April 9). New guidelines call for broad changes in science education. New York Times. Retrieved from http://www.nytimes.com/2013/04/10/science/panel-calls-forbroad-changes-in-science-education.html

Goldenberg, S. (2016, February 11). Two-thirds of US students are taught climate change badly, study finds. The Guardian. Retrieved from https://www.theguardian.com/environment/2016/feb/11/two-thirds-of-us-students-aretaught-climate-change-badly-study-finds 
Hallegatte, S., Bangalore, M., Bonzanigo, L., Fay, M., Kane, T., Narloch, U., ... Vogt-Schilb, A. (2016). Shock waves: Managing the impacts of climate change on poverty. Washington DC: International Bank for Reconstruction and Development / The World Bank.

Hansen, M., Mann, E., \& Valant, J. (2017, May 2). Reflecting on education policy during Trump's first 100 days — and predicting what's next. The Brookings Institution. Retrieved from https://www.brookings.edu/blog/brown-center-chalkboard/2017/05/02/reflectingon-education-policy-during-trumps-first-100-days-and-predicting-whats-next/

Harmon, A. (2017, June 4). Climate science meets a stubborn obstacle: Students. New York Times. Retrieved from https:/www.nytimes.com/2017/06/04/us/education-climatechange-science-class-students.html

Jackson, C. T. (2017). The inequalities of climate change and poverty: Impact analysis and potential solutions. Inquiries Journal, 9(3). Retrieved from http://www.inquiriesjournal.com/articles/1589/the-inequalities-of-climate-change-andpoverty-impact-analysis-and-potential-solutions

Kirk, K. (2017, September 9). Teachers dig in to teach climate change. Yale Climate Connections. Retrieved from https://www.yaleclimateconnections.org/2017/09/returningteachers-dig-in-to-teach-climate-change/

Leary, M. K. (2016). Understanding poverty. Washington DC: World Bank Group. Retrieved from http://www.worldbank.org/en/topic/poverty/overview

Michels, P. (2014, November 25). A new conservative watchdog's big textbook war debut. Texas Observer. Retrieved from https://www.texasobserver.org/roy-white-truth-texastextbooks-sboel

National Aeronautics and Space Administration. (2017). Climate change: How do we know?. Retrieved from https://climate.nasa.gov/evidence/

National Science Teachers Association. (2017) About the Next Generation Science Standards. National Science Teachers Association. Retrieved from http://ngss.nsta.org/About.aspx

NGSS Lead States. (2013). Next generation science standards: For states, by states. The National Academies Press. Retrieved from https://www.nextgenscience.org/

National Research Council of the National Academies. (2015). Guide to implementing the Next Generation Science Standards. Washington, DC: The National Academies Press.

Otto, I., Reckien, D., Reyer, C., Marcus, R., Le Masson, V., Jones, L., ... Serdeczny, O. (2017). Social vulnerability to climate change: A review of concepts and evidence. Regional Environmental Change, 17(6), 1651-1662. 
Plumer, B. (2017, September 20). How can U.S. states fight climate change if Trump quits the Paris Accord? New York Times. Retrieved from https://www.nytimes.com/2017/09/20/climate/paris-climate-accord-trump.html

Provost, C. (2016, October 17). Climate change could drive $122 \mathrm{~m}$ more people into extreme poverty by 2030. The Guardian. Retrieved from https://www.theguardian.com/globaldevelopment/2016/oct/17/climate-change-could-drive-122m-more-people-into-extremepoverty-by-2030-un-united-nations-report

Rawls, J. (Ed.). (2001). Justice as fairness: A restatement. Cambridge: Harvard University Press.

Rawls, J. (1999). A theory of justice. Cambridge: Harvard University Press.

Robelen, E. (2012, May 14). Who is writing the 'Next Generation' Science Standards? Education Week. Retrieved from http://blogs.edweek.org/edweek/curriculum/2012/05/who_is_writing_the_next_genera.ht $\mathrm{ml}$

Stutz, T. (2014, November). Texas Board of Education delays action on textbooks amid revisions. Dallas Morning News. Retrieved from https://www.dallasnews.com/news/education/2014/11/18/texas-board-of-educationdelays-action-on-textbooks-amid-revisions

Truth in American Education. (2017). About us. Truth in American Education. Retrieved from https://truthinamericaneducation.com/about-us/

Truth in Textbooks Coalition. (2015). A summary of findings offactual errors, omissions of facts, half-truths, \& agenda bias in world history, world geography, and world cultures. Boerne, TX: Truth in Textbooks Coalition.

Truth in Textbooks Coalition. (2017). Truth in Texas textbooks. Retrieved from http://truthintexastextbooks.com/

United Nations. (2015). Sustainable development goals: 17 goals to transform our world. New York, NY: United Nations. Retrieved from http://www.un.org/sustainabledevelopment/sustainable-development-goals/

United States Department of Education. (2017). College- and career-ready standards. Washington, DC: US Department of Education. Retrieved from https://www.ed.gov/k12 reforms/standards

Williams, B. (2013, June 18). States have a choice in adopting Common Core Standards for K12 education. Huffington Post. Retrieved from https://www.huffingtonpost.com/bobwilliams/common-core-standards_b_3461006.html

Zhou, X., Chen, J., Li, Z., Wang, G., \& Zhang, F. (in press). Impact assessment of climate change on poverty reduction: A global perspective. Physics and Chemistry of the Earth. $1-10$. 


\section{Appendix A NGSS' Incorporation of Climate Change Education (ACE, 2017)}

\section{Middle School NGSS Performance Expectations}

Physical Science

- MS-PS1 Matter and Its Interactions

- MS-PS1-3. Gather and make sense of information to describe that synthetic materials come from natural resources and impact society.

Life Science

- MS-LS1 From Molecules to Organisms: Structures and Processes

- MS-LS1-6. Construct a scientific explanation based on evidence for the role of photosynthesis in the cycling of matter and flow of energy into and out of organisms.

Earth and Space Science

- MS-ESS3: Earth and Human Activity

- MS-ESS3-3. Apply scientific principles to design a method for monitoring and minimizing a human impact on the environment

- MS-ESS3-4. Construct an argument supported by evidence for how increases in human population and per-capita consumption of natural resources impact Earth's systems.

- MS-ESS3-5. Ask questions to clarify evidence of the factors that have caused the rise in global temperatures over the past century.

\section{High School NGSS Performance Expectations}

Physical Science

- HS-PS3 Energy

- HS-PS3-3. Design, build, and refine a device that works within given constraints to convert one form of energy into another form of energy.

- HS-PS4 Waves and Their Applications in Technologies for Information Transfer

- HS-PS4-4. Evaluate the validity and reliability of claims in published materials of the effects that different frequencies of electromagnetic radiation have when absorbed by matter.

Life Science

- HS-LS2 Ecosystems: Interactions, Energy, and Dynamics

- HS-LS2-1. Use mathematical and/or computational representations to support explanations of factors that affect carrying capacity of ecosystems at different scales.

- HS-LS2-5. Develop a model to illustrate the role of photosynthesis and cellular respiration in the cycling of carbon among the biosphere, atmosphere, hydrosphere, and geosphere.

- HS-LS2-6. Evaluate the claims, evidence, and reasoning that the complex interactions in ecosystems maintain relatively consistent numbers and types of organisms in stable conditions, but changing conditions may result in a new ecosystem. 
Earth and Space Science

- HS-ESS2 Earth's Systems

- HS-ESS2-2. Analyze geoscience data to make the claim that one change to Earth's surface can create feedbacks that cause changes to other Earth's systems.

- HS-ESS2-4. Use a model to describe how variations in the flow of energy into and out of Earth's systems result in changes in climate.

- HS-ESS2-6. Develop a quantitative model to describe the cycling of carbon among the hydrosphere, atmosphere, geosphere, and biosphere.

- HS-ESS2-7. Construct an argument based on evidence about the simultaneous coevolution of Earth's systems and life on Earth.

- HS-ESS3 Earth and Human Activity

- HS-ESS3-1. Construct an explanation based on evidence for how the availability of natural resources, occurrence of natural hazards, and changes in climate have influenced human activity.

- HS-ESS3-2. Evaluate competing design solutions for developing, managing, and utilizing energy and mineral resources based on cost-benefit ratios.

- HS-ESS3-4. Evaluate or refine a technological solution that reduces impacts of human activities on natural systems.

- HS-ESS3-5. Analyze geoscience data and the results from global climate models to make an evidence-based forecast of the current rate of global or regional climate change and associated future impacts to Earth systems.

- HS-ESS3-6. Use a computational representation to illustrate the relationships among Earth systems and how those relationships are being modified due to human activity.

Engineering Design

- HS-ETS1 Engineering Design

- HS-ETS1-2. Design a solution to a complex real-world problem by breaking it down into smaller, more manageable problems that can be solved through engineering. 